$621.941 .027: 539.411 .011$

\title{
Compressive Strength of the Cutting Edges of the WC-Co Cemented Carbides*
}

\author{
By Kazuaki Masuda**
}

\begin{abstract}
Magnitudes of the stresses in the cutting edge during machining metals were calculated applying stress functions based on the theory of elasticity, and the accuracy of calculation was testified by the experiments on the destruction of the actual cutting edges under certain cutting conditions.

In the case of machining chilled cast iron with some WC-Co cemented carbides, the results of two experiments are compared with the theoretical values.

The two tests are carried out with the following purposes: low.

1. To find the minimum lip angle which endures the cutting force when the cutting speed is

2. To find the compressive strength of cutting edge for the destruction due to thermal softening when the lip angle is constant.

The theoretical values are found to be in good agreement with the experimental values in spite of many hypotheses.
\end{abstract}

\section{Introduction}

When machining the chilled rolls with single point tools made of various tool materials, there occur failures of cutting edges made of $\alpha-\mathrm{Al}_{2} \mathrm{O}_{3}$ (Oxide tools) or of $\mathrm{TiC}-\mathrm{Ni}$ (thermet tools) having higher hot hardness and higher temperature resistance than WC-Co (carbide tools). It has been reasoned so far that the failures were due to the lack of toughness. But author considers that the compressive strength is important because WC-Co cemented carbides having low transverse rupture strength due to low cobalt content can stand suf. ficiently long use.

On the other hand, the stresses in the cutting edge during machining can be computed by means of the stress function of two-dimensional elastic theory ${ }^{(1)}$, but the results of these calculations have not been used to confirm the presence of the failures of cutting edge under the practical cutting conditions.

It may need a considerably bold assumption to analyze the stresses in the cutting edge, because as far as cemented carbides are concerned, the value of their tensile strength differs greatly from their compressive strength and the distributions of the

* Received 3 rd September, 1968.

** Chief of Cemented Carbide Products Salessection, Osaka Metal Products Sales Office, Mitsubishi Metal Mining Co. Ltd. Kita-ku, Osaka. cutting forces and the temperatures on the rake face have not been confirmed. However, in this paper, the theoretical values are compared with the experimental values of the compressive stresses under which the cutting edges begin to fail during machining of chilled cast iron.

\section{Method of experiment}

\subsection{Summary of experiment}

Two experiments were carried out based on the fact that during machining of chilled cast iron the cutting forces are constant independently of the tool materials if the rake angle is kept constant.

(1) To measure the minimum values of the lip angles at which the cutting edges begin to fail for various carbides while keeping the rake angle constant and increasing the relief angles gradually in order to compare them with the theoretical values.

The test is carried out keeping the cutting speed low in order to avoid the thermal softening of the cutting edge.

(2) To compare the experimental values of hot compressive strengths with theoretical values in the cutting edges after the following procedure.

First, to measure the minimum cutting speeds when the cutting edges begin to fail due to thermal softening for various carbides while keeping the rake angle and relief angle constant.

Second, to calculate the hot compressive strength 
at the critical cutting speed by examining the follow. ing relations; the cutting speed-temperature in the cutting edge, temperature-hot hardness of carbides and hardness-compressive strength of the carbides.

When calculating the stresses in a cutting edge, the following assumptions were made.

a. The friction at the initial wear band $(0.1$ $\mathrm{mm}$ or so) on the clearance face can be ignored.

b. The temperature distribution is uniform over the rake face.

c. The distribution of the cutting forces over the rake face are uniform. The effect of the nose radius and the end cutting edge on the forces can be ignored.

d. The compressive strength of WC-Co cemented carbides is proportional to its hardness.

\subsection{Equipment for experiment}

The equipments used in the tests were as follows.

a. Lathe; Wöhrenberg Hannover E $3540 \mathrm{~kW}$.

b. Rake face temperature measuring device.

b-1 Tool-work thermocouple method.

b-2 Synchroscope (Iwasaki Tsusin Co.)

c. Hot hardness measuring device; Micro-Vikers hot hardness tester (Akashi Seisaku Co.)

d. Compressive strength measuring device; Olsen universal testing machine.

e. Cutting force measuring device; Electric wire strain gauge, pen-recorder. (Shinko Tsusin Co.)

\subsection{Tool}

Tool materials are binary WC-Co cemented carbides with various contents of Co. Their specific characteristic properties are listed in Table. 1.

The tool geometry is as follows; Back and side rake angle $0^{\circ}$, end and side relief angle $5^{\circ}$, end cutting edge angle $8^{\circ}$, side cutting edge angle $0^{\circ}$, and nose radius $0.5 \mathrm{~mm}$.

In order to avoid the influence of stresses caused

Table 1 Properties of cemented carbides used in tests

\begin{tabular}{c|c|c|c|c|c}
\hline \hline Mark & $\begin{array}{c}\text { Co } \\
\text { content } \\
\text { Wt \% }\end{array}$ & $\begin{array}{c}\text { WC } \\
\text { grain } \\
\text { size }\end{array}$ & $\begin{array}{c}\text { Vickers } \\
\text { hardness } \\
H_{V 0.3}\end{array}$ & $\begin{array}{c}\text { Compres- } \\
\text { sive } \\
\text { strength } \\
\mathrm{kg} / \mathrm{mm}^{2}\end{array}$ & $\begin{array}{c}\text { Bending } \\
\text { strength } \\
\mathrm{kg} / \mathrm{mm}^{2}\end{array}$ \\
\hline $\mathrm{H}-1$ & 4.5 & Fine & 2146 & 582 & 136.1 \\
\hline $\mathrm{H}-2$ & 6.0 & Fine & 2093 & 573 & 152.5 \\
\hline $\mathrm{H}-3$ & 6.0 & Medium & 1796 & 525 & 166.8 \\
\hline $\mathrm{H}-4$ & 6.0 & Coarse & 1710 & 489 & 180.5 \\
\hline $\mathrm{H}-5$ & 9.0 & Coarse & 1661 & 461 & 198.3 \\
\hline $\mathrm{H}-6$ & 12.0 & Coarse & 1446 & 436 & 225.1 \\
\hline
\end{tabular}

Table 2 Compositions of the low alloyed chilled roll

\begin{tabular}{c|c|c|c|c|c|c}
\hline \hline $\mathrm{C}$ & $\mathrm{Si}$ & $\mathrm{Mn}$ & $\mathrm{P}$ & $\mathrm{S}$ & $\mathrm{Ni}$ & $\mathrm{Cr}$ \\
\hline 3.49 & 0.52 & 0.21 & 0.26 & 0.074 & 1.13 & 0.41 \\
\hline
\end{tabular}

by brazing, the carbide tips with a thickness of 4.5 $\mathrm{mm}$ are clamped mechanically on the holder of $25 \times$ $25 \mathrm{~mm}$.

\section{$2 \cdot 4$ Work material}

Compressive failure of cutting edge is observed during machining of not only chilled cast iron but also of high strength-thermal resistant alloys and tempered steel. But in order to study only about compressive failures the former material seems to have such a very convenient nature as follows.

(1) The major structural component being cementite, the chilled cast iron is affected little by chemical reaction or diffusion. So the failure of the cutting edge during machining of this material is due mainly to mechanical factors.

(2) The cutting force remains almost constant, independently of the tool materials and the cutting speed. It seems reasonable to assume that the chiptool interface area of the rake face is constant.

(3) The chip-tool interface temperature on the rake face remains almost constant independently of the tool materials.

The work material is an alloyed chilled roll made by Nippon Roll Co., with its compositions as listed in Table 2. Figure 1 shows the relation of the distances from the outer circle and the hardness along four radii perpendicular to each other in a section of the roll.

The figure shows that the outer part forms a solid shell about $14 \mathrm{~mm}$ thick outside the soft inner part, and that the hardness ranges from 51.2 to $51.8 \mathrm{HRC}$. In this testing, the roll was used after cutting off the outermost part by a thickness of $5 \mathrm{~mm}$, so as to get id of the especially hardened part.

\section{Stresses in the cutting edge}

\subsection{Theoretical equation to calculate the} stresses

There has been no established theory as to the distribution of the cutting force on the cutting edge during machining. But the theoretical approach to the metal cutting mechanics is generally made on

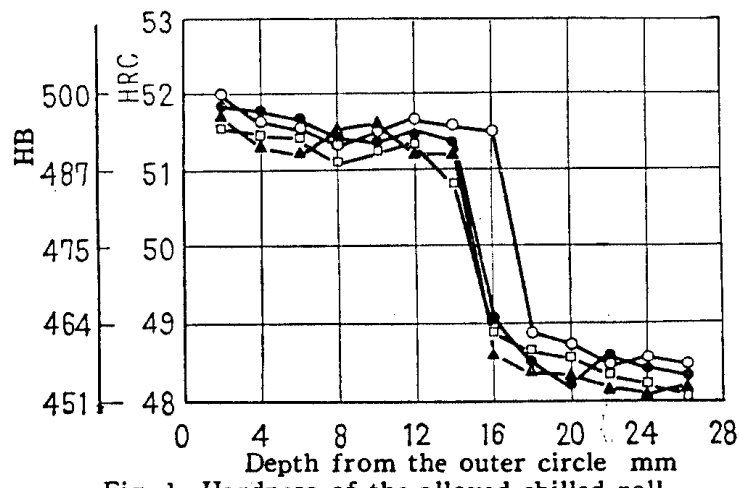

Fig. 1 Hardness of the alloyed chilled roll 
the assumption that the normal forces and the friction forces distribute uniformly on the cutting edge.

Based on this assumption, the cutting edge is compared to a wedge as illustrated in Fig. 2, and the stresses are calculated by means of the stress function of two-dimensional elastic theory (2) as follows.

$$
\begin{aligned}
\phi= & a_{0} \log r+b_{0} r^{2}+c_{0} r^{2} \log r+d_{0} r^{2} \theta+a_{0}{ }_{0} \theta \\
& +\frac{a_{1}}{2} r \theta \sin \theta+\left(b_{1} r^{3}+a_{1}{ }_{1} r^{-1}+b^{\prime}{ }_{1} r \log r\right) \cos \theta \\
& -\frac{c_{1}}{2} r \theta \cos \theta+\left(d_{1} r^{-3}+c^{\prime}{ }_{1} r^{-1}+d^{\prime}{ }_{1} r \log r\right) \sin \theta \\
& +\sum_{n=2}^{\infty}\left(a_{n} r^{n}+b_{n} r^{n+2}+a^{\prime}{ }_{n} r^{-n}+b^{\prime}{ }_{n} r^{-n+2}\right) \cos n \theta \\
& +\sum_{n+2}^{\infty}\left(c_{n} r^{n}+d_{n} r^{n+2}+c_{n}{ }^{\prime} r^{-n}+d_{n}{ }^{\prime} r^{-n+2}\right) \sin n \theta
\end{aligned}
$$

The stress components are given by

$$
\left.\begin{array}{l}
\sigma_{r}=\frac{1}{r} \frac{\partial \phi}{\partial r}+\frac{1}{r^{2}} \frac{\partial^{2} \phi}{\partial \theta^{2}} \\
\sigma_{r}=\frac{\partial^{2} \phi}{\partial r^{2}} \\
\tau_{r \theta}=\frac{1}{r^{2}} \frac{\partial \phi}{\partial \theta}-\frac{1}{r} \frac{\partial^{2} \phi}{\partial r \partial \theta}
\end{array}\right)
$$

And taking only the terms containing $r^{n}(n \geqq \theta)$

$$
\begin{aligned}
\sigma_{r}= & 2 b_{0}+2 d_{0} \theta-2 a_{2} \cos 2 \theta-2 c_{2} \sin 2 \theta \\
& +r\left(2 b_{1} \cos \theta+2 d_{1} \sin \theta-6 a_{3} \cos 3 \theta-6 c_{3} \sin 3 \theta\right) \\
& -12 r^{2}\left(a_{4} \cos 4 \theta+c_{4} \sin 4 \theta\right)+\cdots \cdots \cdots \cdots(3) \\
\sigma_{\theta}= & 2 b_{0}+2 d_{0} \theta+2 a_{2} \cos 2 \theta+2 c_{2} \sin 2 \theta \\
& +6 r\left(b_{1} \cos \theta+d_{1} \sin \theta+a_{3} \cos 3 \theta+c_{3} \sin 3 \theta\right) \\
& +12 r^{2}\left(b_{2} \cos 2 \theta+d_{2} \sin 2 \theta+a_{4} \cos 4 \theta\right. \\
& \left.+c_{4} \sin 4 \theta\right)+\cdots \cdots \cdots \cdots \cdots \cdots \cdots \cdots \cdots \cdots \cdots \cdots \cdots \cdots \cdots \cdots(4) \\
\tau_{r \theta}= & -d_{0}+2 a_{2} \sin 2 \theta-2 c_{2} \cos 2 \theta \\
& +r\left(2 b_{1} \sin \theta-2 d_{1} \cos \theta\right. \\
& \left.+6 a_{3} \sin 3 \theta-6 c_{3} \cos 3 \theta\right) \\
& +r^{2}\left(6 b_{2} \sin 2 \theta-6 d_{2} \cos 2 \theta\right. \\
& \left.+12 a_{4} \sin 4 \theta-12 c_{4} \cos 4 \theta\right)+\cdots \cdots \cdots \cdots \cdots(5)
\end{aligned}
$$

and changing the values of the stresses into non-

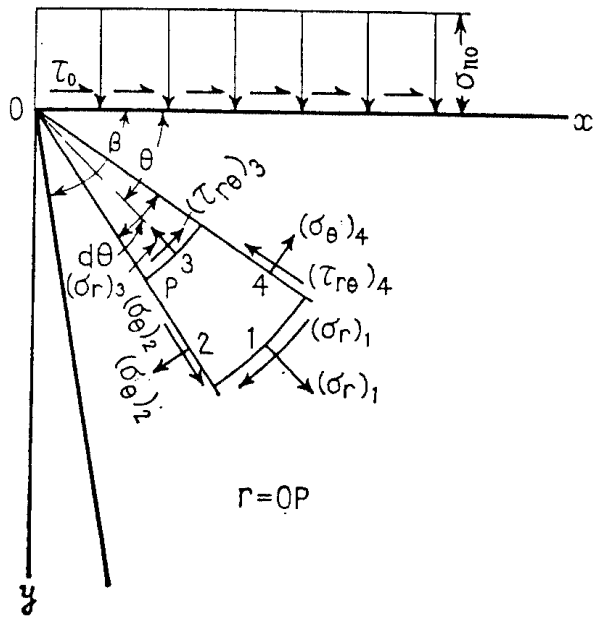

Fig. 2 Stress in wedge dimension, the normal load per unit area of the rake face is given as $\sigma_{n \theta}=-1$; and the frictional load is given as $\tau_{0}=-K$, where $K$ is a coefficient of friction. The distribution of the stresses being assumed to be uniform, all the constants containing $r$ such as $b_{1}, d_{1}, a_{3}, c_{3}, b_{2}, d_{2}, a_{4}$ and $c_{4}$ on the right sides of $\sigma_{r} \sigma_{0}$ and $\tau_{r 0}$ are zero.

With the edge point identified as an origin, the boundary conditions are given by

$$
\left.\begin{array}{l}
\sigma_{\theta(\theta=0)}=-1 \\
\tau_{r \theta(\theta=0)}=-K \\
\sigma_{\theta(\theta=\beta)}=0 \\
\tau_{r \theta(\theta=\beta)}=0
\end{array}\right\}
$$

where $\beta$ is a lip angle of the cutting tool.

Comparing Eqs. (4) and (5) with ( 6 ), the following equations are given

$$
\begin{aligned}
& 2 b_{0}+2 a_{2}=-1 \\
& 2 b_{0}+2 d_{0} \beta+2 a_{2} \cos 2 \beta+2 c_{2} \sin 2 \beta=0 \\
& -2 c_{2}-d_{0}=-K \\
& -d_{0}+2 a_{2} \sin 2 \beta-2 c_{2} \cos 2 \beta=0
\end{aligned}
$$

Solving these equations, the constants are given by:

$$
\begin{aligned}
a_{2} & =\left(K \cos \beta-\sin \beta+2 K \beta \sin \beta-\frac{K \beta}{\sin \beta}\right) / \\
4 & (\sin \beta-\beta \cos \beta) \\
d_{0} & =2(K \sin \beta-\cos \beta) / 4(\sin \beta-\beta \cos \beta) \\
c_{2} & =(\cos \beta-2 K \beta \cos \beta+K \sin \beta) / \\
& 4(\sin \beta-\beta \cos \beta) \\
b_{0} & =(-\sin \beta+2 \beta \cos \beta-K \cos \beta \\
& \left.-2 K \beta \sin \beta+\frac{K \beta}{\sin \beta}\right) / 4(\sin \beta-\beta \cos \beta)
\end{aligned}
$$

When the non-dimensionalized stresses are expressed by adding * on the right shoulder of every letter, two principal stresses are given by

$$
\left.\begin{array}{l}
\sigma_{1}^{*}=\frac{\sigma_{r}^{*}+\sigma_{\theta}^{*}}{2}+\sqrt{\left(\frac{\sigma_{r}^{*}-\sigma_{\theta}^{*}}{2}\right)^{2}+\tau_{r \theta}^{* 2}} \\
\sigma_{2} *=\frac{\sigma_{r}^{*}+\sigma_{\theta}^{*}}{2}-\sqrt{\left(\frac{\sigma_{r}^{*}-\sigma_{\theta}^{*}}{2}\right)^{2}+\tau_{r \theta}^{* 2}}
\end{array}\right\}
$$

3.2 Experiments to decide the intensities of the loads acting on the rake face

Figure 3 shows the values of the cutting force for various tool materials. The values are nearly constant independently of the tool materials, unless the plastic deformation of the cutting edge elevates the cutting force to the excessive cutting speed. The main cutting force is $70.1 \mathrm{~kg} / \mathrm{mm}$ and the feed force is $30.5 \mathrm{~kg} / \mathrm{mm}$.

Therefore, the so-called coefficient of friction on the chip-tool interface is given by $K=0.431$.

During the machining of the chilled roll, chip appears in the shape of "saw-teeth" as presented in Fig. 4. Therefore, the cutting edge is subjected to. a wide variation of the cutting force intensity as: 


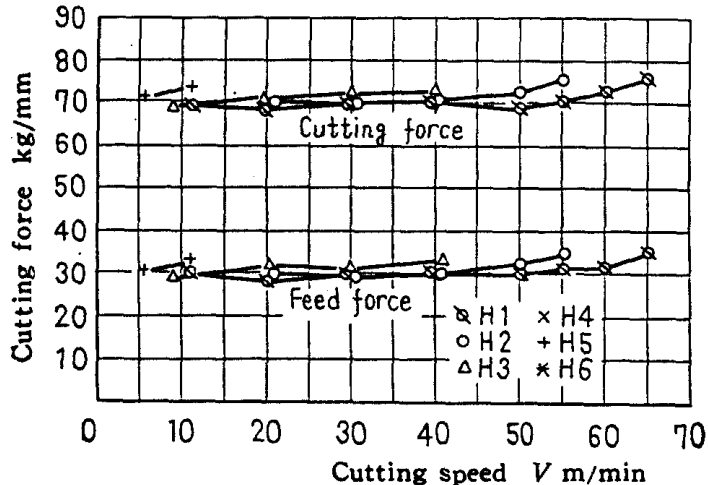

Tool geometry: $0,0,5,5,8,0,0.5$

Depth of cut: $2 \mathrm{~mm}$, Feed rate: $0.19 \mathrm{~mm} / \mathrm{rev}$

Fig. 3 Cutting forces by various tool materials

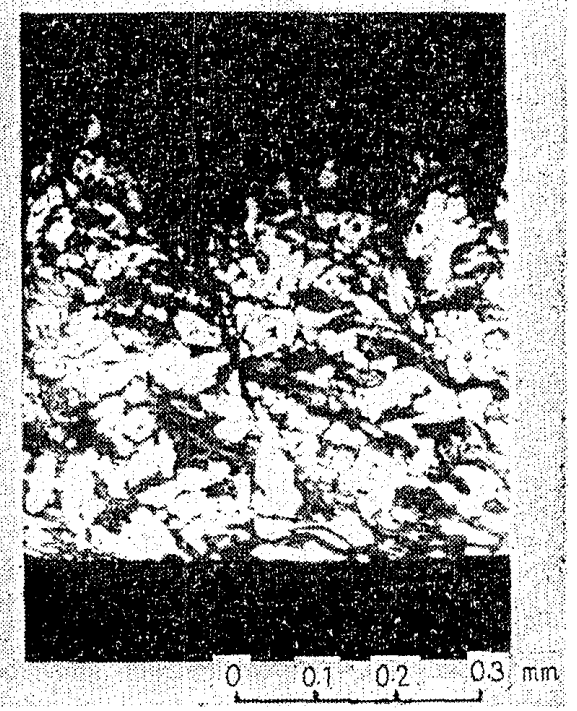

Work material: alloyed chilled roll

Tool material: H-3

Tool geometry: $0,0,5,5,8,0,0.5$

Depth of cut: $2 \mathrm{~mm}$

Feed rate: $0,19 \mathrm{~mm} / \mathrm{rev}$

Cutting speed: $20 \mathrm{~m} / \mathrm{min}$

Fig. 4 Cross section of the chip

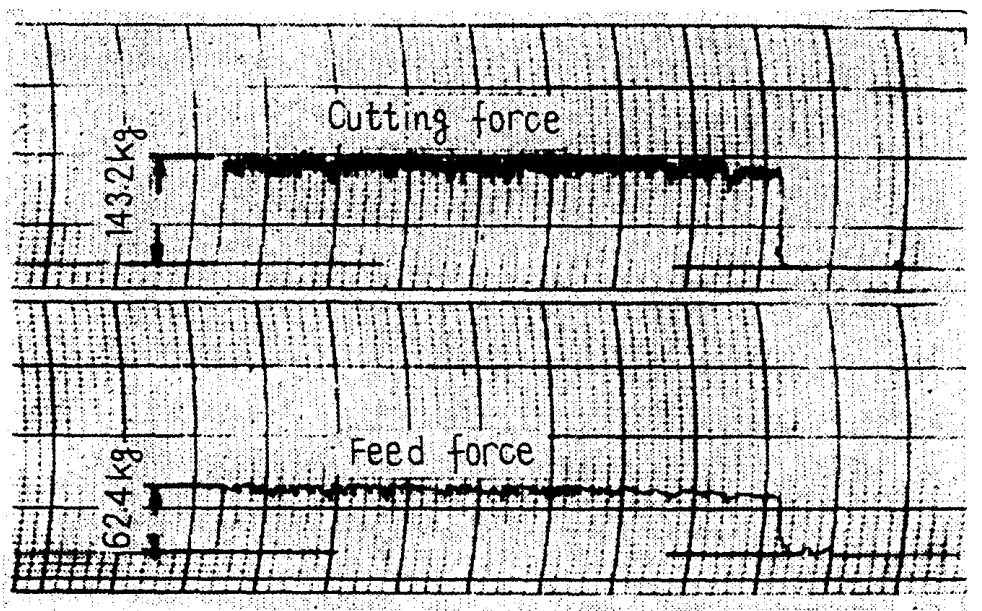

Cutting conditions are the same as Fig. 4

Fig. 5 Variation of cutting forces shown in Fig. 5.

The values in Fig. 3 show the maximum values of variations. As soon as the cutting edge touches the work at the first stage of machining, the flank face wears to a certain extent. This phenomenon is inevitable in cutting hard materials, and in the case of chilled cast iron, the cutting force increases in proportion to the width of the flank wear band as shown in Fig 6.

So in this test, the values of the cutting forces with initial wear band of 0.05 to $0.1 \mathrm{~mm}$ in width are adopted as those machined with a cutting edge which is ideally sharp.

The extent of the cutting force acting on the rake face can be inferred from the trace of the chiptool contact left on the rake face. The picture of a section of the cutting edge (Fig. 16 in 4.2), which was deformed plastically due to the cutting force, shows that the extent is observed to be $0.259 \mathrm{~mm}$ wide from the cutting edge for feed rate $0.19 \mathrm{~mm} / \mathrm{rev}$.

Accordingly, the normal load on the rake face is estimated as follows ;

$\sigma_{n 0}=70.1 \mathrm{~kg} / \mathrm{mm} / 0.259 \mathrm{~mm}=270 \mathrm{~kg} / \mathrm{mm}^{2}$

The compressive strength and the transverse rupture strength for various carbides shown in Table
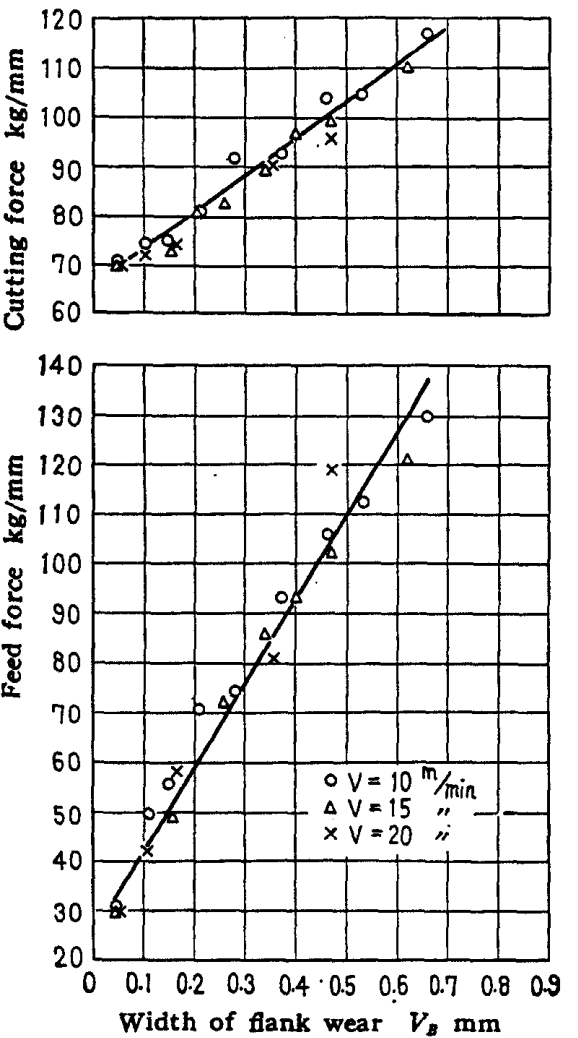

Cutting conditions are the same as Fig. 1

Fig. 6 Width of flank wear versus cutting force 
1 are divided by $270 \mathrm{~kg} / \mathrm{mm}^{2}$ and calculated in nondimensional terms of the converted bending rupture strength and the compressive strength as shown in Table 3.

\subsection{Calculated result of stresses}

Taking the lip angle of $85 \mathrm{deg}$ (rake angle: 0 deg, relief angle: $5 \mathrm{deg}$ ), the load on the rake face $\sigma_{n 0}=-1$, coefficient of friction $K=0.431$ and lip angle $\beta=1.4835$ radian are substituted in equations (5), (8) and (9).

And the results of the calculation of the stresses are shown in Fig. 7 (a).

In this case both $\sigma_{1}$ and $\sigma_{2}$ are found to be on the side of compression. But the calculation for various values of $\beta$ proves that as the angle decreases, the principal stress $\sigma_{1}$ on the side of the rake face has higher values on tensile side [see Fig. 7 (b)].

\subsection{Condition of failure}

Then the criterion for the failure of carbide cutting edge must be analyzed by using those stresses calculated above. According to the Mohr's maximum shear stress theory (3), the criterion for failure $\left(\sigma_{1}^{*}-\sigma_{2}^{*}\right) / 2$ is assumed to be affected by the normal stress $\left(\sigma_{1}^{*}+\sigma_{2}^{*}\right) / 2$.

So, $\left(\sigma_{1}^{*}-\sigma_{2}^{*}\right) / 2=f\left(\sigma^{*}\right)$

It is necessary to make further assumption for simplification. By testing the uniaxial tensile strength and the uniaxial compressive strength, circle A and B which are the maximum stress circles of the critical failure are found as illustrated in Fig. 8. Then the common tangent line $A B$ of both circles is assumed to be the critical line. That is to say, when the values of the normal stress at the arbitrary point in the cutting edge are given by $\left(\sigma_{1}^{*}+\sigma_{2}^{*}\right) / 2=\sigma_{a}^{*}$, after finding the length of $\mathrm{O}_{3} \mathrm{C}$ which is obtained by drawing a perpendicular line to the common tangent line $\mathrm{AB}$ from the point $\sigma_{a}{ }^{*}$ on the abscissa $\sigma$, the value of $\mathrm{O}_{3} \mathrm{C}$ is compared with computed value $\left(\sigma_{1}{ }^{*}-\sigma_{2}{ }^{*}\right) / 2$. When the value of $\left(\sigma_{1}^{*}-\sigma_{2}^{*}\right)$ becomes larger than the value of $2 \mathrm{O}_{3} \mathrm{C}$, it is assumed that a failure occurs.

In the case of cemented carbides, it is known that the value of tensile strength is about half that of transverse rupture strength. The reason for this has not been clarified yet, but because of the similarity between the stress distribution in the test piece of bending test and that of cutting edge, it is considered more practical to use the value of transverse rupture strength, which was employed as the radius of the circle $0_{1}$.

Figure 9 shows the values of $\sigma_{1}^{*}, \sigma_{2}^{*},\left(\sigma_{1}^{*}\right.$ $\left.\sigma_{2}^{*}\right),\left(\sigma_{1}^{*}+\sigma_{2}^{*}\right) / 2$ for various lip angles. It is found from these diagrams that $\left(\sigma_{1}^{*}-\sigma_{2}^{*}\right)$ becomes larger on both rake face and flank face than in middle section. Figure 10, representing the values of $\left(\sigma_{1}^{*}-\sigma_{2}^{*}\right)$ on both sides of the wedge, shows that the value on the flank face becomes occasionally

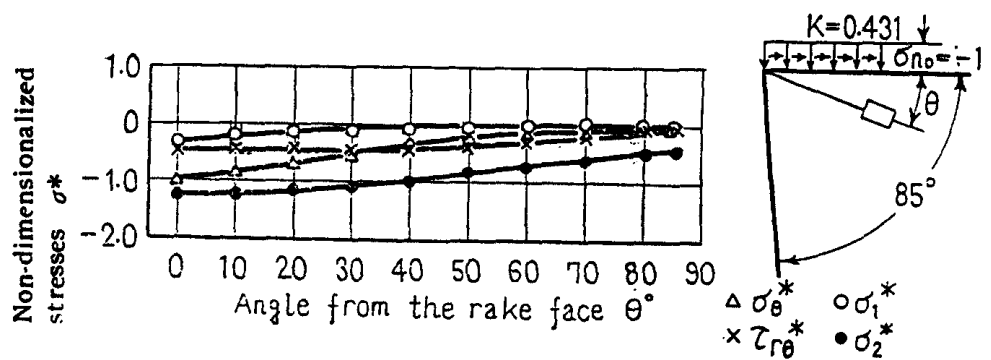

(a) Stresses for lip angle $85^{\circ}$

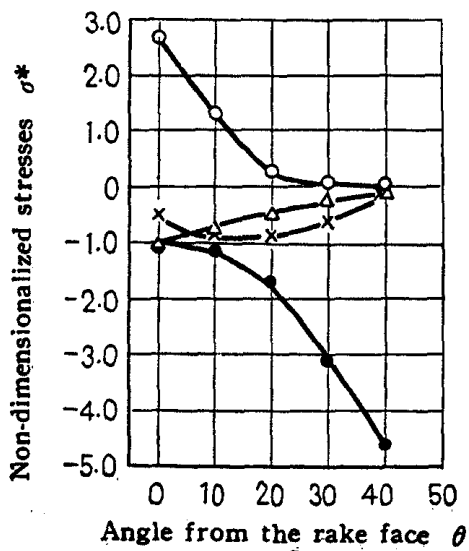

(b) Stresses for lip angle $40^{\circ}$

Fig. 7

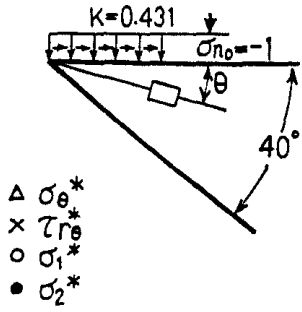
$\times \tau_{r \theta}^{*} \cdot \sigma_{2}^{*}$ larger than that on rake face. But $\left(\sigma_{1}^{*}\right.$ $\left.+\sigma_{2}{ }^{*}\right) / 2$ is negative (compression) on the side of flank face and positive (tension) on the side of rake face. The tempera. ture of the rake face is always higher than that of the flank face during machining. Taking all these things into consideration, it is assumed that the stresses on the side of the rake face play an im. portant role in the failure of the cutting edge.

Both values of $\left(\sigma_{1}^{*}-\sigma_{2}^{*}\right)$ on the rake

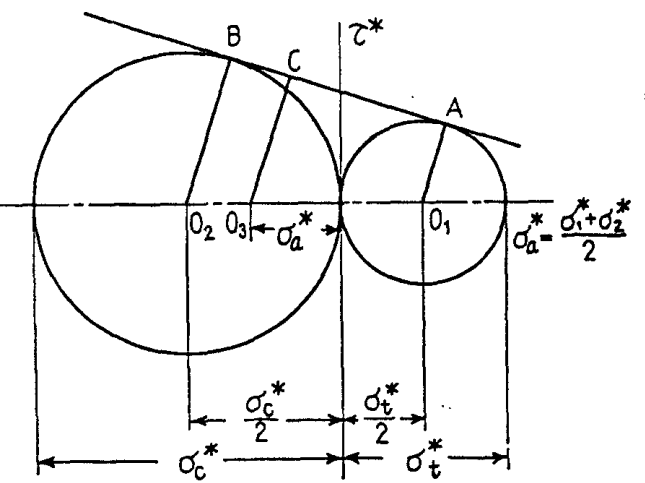

Fig. 8 Mohr's circle of stress 


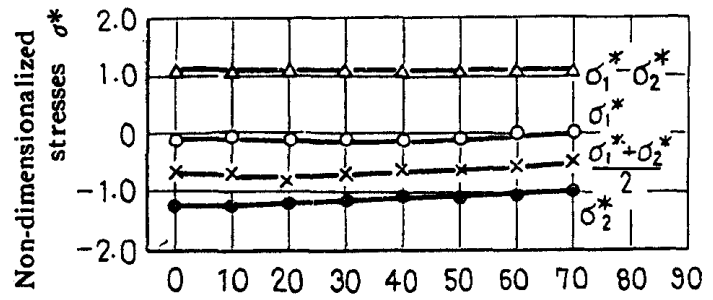

Angle from the rake face $\theta^{\circ}$

(a) Lip angle $70^{\circ}$

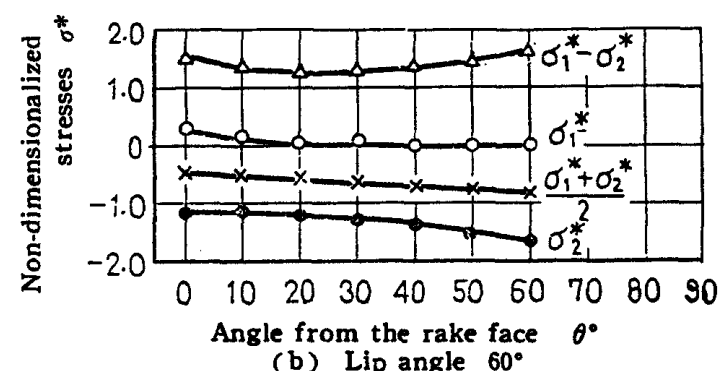

(b) Lip angle $60^{\circ}$

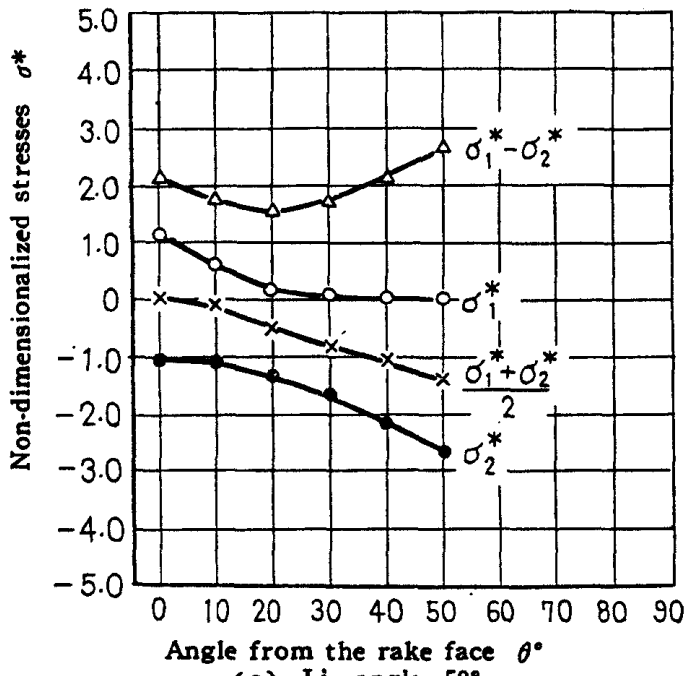

(c) Lip angle $50^{\circ}$

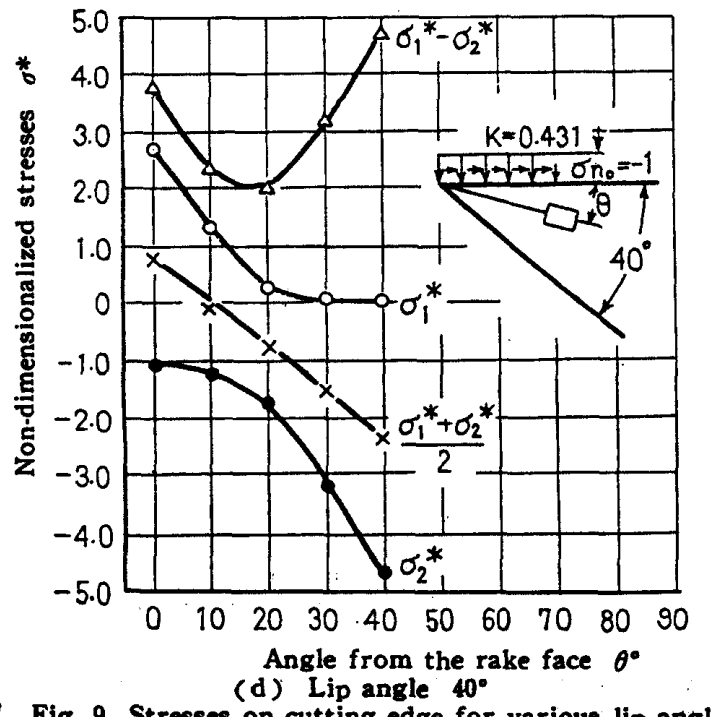

Fig. 9 Stresses on cutting edge for various lip angles face and on the flank face vary hyperbolically. Especially, on the side of rake face $\left(\sigma_{1}^{*}-\sigma_{2}{ }^{*}\right)$ decreases slightly as the lip angle increases above 80 deg, while the value increases steeply below the lip angle of $60^{\circ}$ as the angle decreases.

\section{Experiment to examine the conditions} for occurrence of a failure of the cutting edge

\subsection{Examination of the critical lip angle}

The minimum lip angle, at which the failure (as shown in Fig. 11) did not occur within the first 5 minutes of the machining while keeping rake angle at $0^{\circ}$, and at the low cutting speed, was measured three times for each of tool materials and the mean values are listed in Table 3 . In this Table the experimental values are compared with the theoretical ones, the latter being calculated through the following process on the assumption that both transverse rupture strength and compressive strength are the same as those at room temperature, although the actual temperature on the rake face is supposed to be about $240^{\circ} \mathrm{C}$ (see Fig.

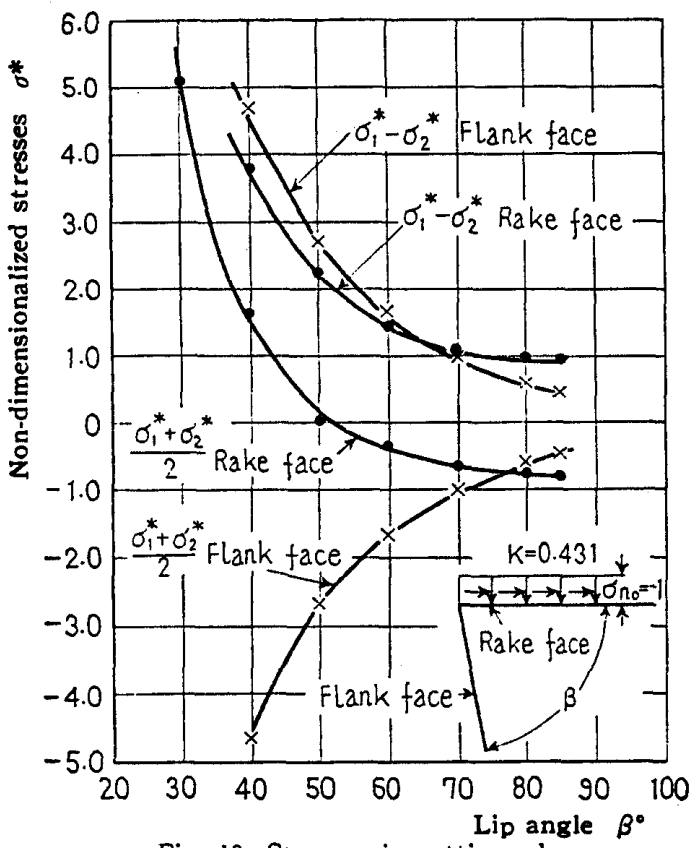

Fig. 10 Stresses in cutting edge

End relief face

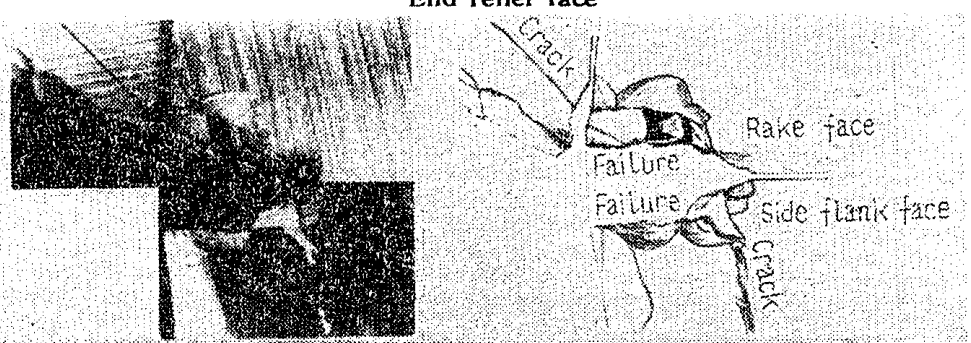

Fig. 11 State of cutting edge failure at small lip angle 
18) under the experimental cutting speed.

Figure 12 shows the critical curve obtained by the method shown in Fig. 8, using the value $\left(\sigma_{1}{ }^{*}+\right.$

Table 3 Critical lip angle

Work material: alloyed chilled roll

Tool geometry: 0,0 , var., $5,8,0,0.5$

Depth of cut: $2 \mathrm{~mm}$, Feed rate: $0.19 \mathrm{~mm} / \mathrm{rev}$

Cutting speed: $2 \mathrm{~m} / \mathrm{min}$, Cutting time: $5 \mathrm{sec}$.

\begin{tabular}{l|c|c|c|c}
\hline & & & \multicolumn{2}{|c}{$\begin{array}{c}\text { Critical lip } \\
\text { angle }\end{array}$} \\
\hline Mark & $\begin{array}{l}\text { Compressive } \\
\text { strength }\end{array}$ & $\begin{array}{l}\text { Bending } \\
\text { strength }\end{array}$ & $\begin{array}{l}\text { Theoret ical } \\
\text { value }\end{array}$ & $\begin{array}{l}\text { Experimen- } \\
\text { tal value }\end{array}$ \\
\hline $\mathrm{H}-1$ & 2.16 & 0.503 & $61.5^{\circ}$ & $62.0^{\circ}$ \\
\hline $\mathrm{H}-2$ & 2.12 & 0.565 & $61.0^{\circ}$ & $62.0^{\circ}$ \\
\hline $\mathrm{H}-3$ & 1.94 & 0.617 & $61.0^{\circ}$ & $60.0^{\circ}$ \\
\hline $\mathrm{H}-4$ & 1.83 & 0.669 & $61.0^{\circ}$ & $60.0^{\circ}$ \\
\hline $\mathrm{H}-5$ & 1.71 & 0.735 & $60.5^{\circ}$ & $58.0^{\circ}$ \\
\hline $\mathrm{H}-6$ & 1.61 & 0.834 & $60.0^{\circ}$ & $55.0^{\circ}$ \\
\hline \multicolumn{3}{c}{ Note : from Table $1 \sigma_{n 0}=270 \mathrm{~kg} / \mathrm{mm}$} \\
\hline
\end{tabular}

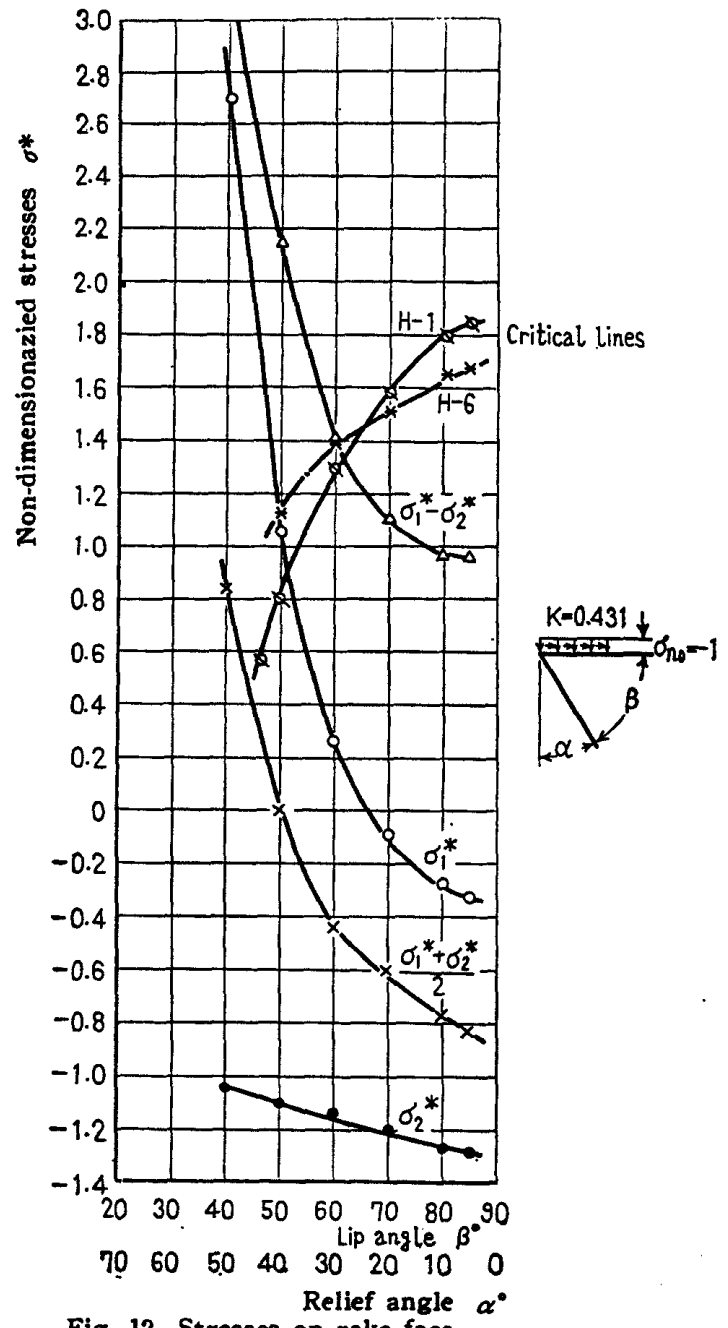

Fig. 12 Stresses on rake face $\left.\sigma_{2}^{*}\right) / 2$ of the rake face shown in Fig. 10 and $\sigma_{t}^{*}\left(=\sigma_{b}{ }^{*}\right)$ and $\sigma_{c}{ }^{*}$ listed in Table 3. This figure shows the critical curve of $\mathrm{H}-1$ whose $\mathrm{Co}_{0}$ content is the lowest and that of $\mathrm{H}-6$ which has the high est $C_{0}$ content.

The minimum lip angles at which the failure of the cutting edge does not occur are given by the intersecting points of those curves and that of $\left(\sigma_{1}{ }^{*}-\right.$ $\sigma_{2}^{*}$ ).

When the $C_{0}$ content of cemented carbide is low, the experimental values coincide very well with the theoretical values owing to the clear failure of the cutting edge, but when the $C_{0}$ content is higher than $\mathrm{H}-5$, the experimental critical lip angle becomes smaller than the theoretical one, due to the obscurity of the failure. But roughly speaking, both of the values coincide very well.

4.2 Investigation of compressive strength when the cutting edge fails owing to the thermal softening

Figure 10 shows that at the lip angle $85 \mathrm{deg}$ the normal stress $\left(\sigma_{1}{ }^{*}+\sigma_{2}{ }^{*}\right) / 2$ is on the side of the compression and the shearing stress $\left(\sigma_{1}^{*}-\sigma_{2}^{*}\right)$ is small.

Accordingly, it is proved that a breakage does not occur at the cutting edge made of cemented carbide when the angles are about 85 deg. But a breakage of the cutting edge is expected as the temperature of the cutting edge gets higher causing a decrease of yield stress due to thermal softening.

When the cutting speed for the chilled roll increases gradually, the wear increases steeply above certain speeds which depend on the tool materials as shown in Fig. 13 and when the tool materials have low Co content, the flaking develops conchoidally on the rake face, or the chipping of the cutting edge as shown Fig. 14 (c) comes to be observed

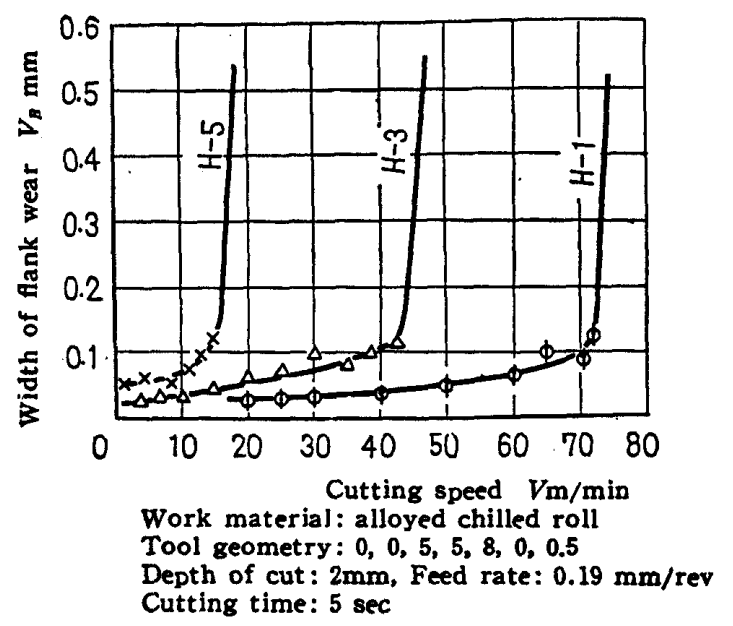

Fig. 13 Width of wear on flank face for various cemented carbides 
Figure 14 (d) shows the breakage on the cutting edge after long machining at lower cutting speed. The comparison of Fig. 14 (c) and (d) proves that the failure of the former is due to the compres. sive deformation of the cutting edge.

The relation of the hardness at room temperature to the critical cutting speed for various tool materials is shown in Fig. 15 showing the critical speed almost in exact proportion to the hardness with one exception of H-5, which is slightly off the line.

Figure 16, showing the section perpendicular to

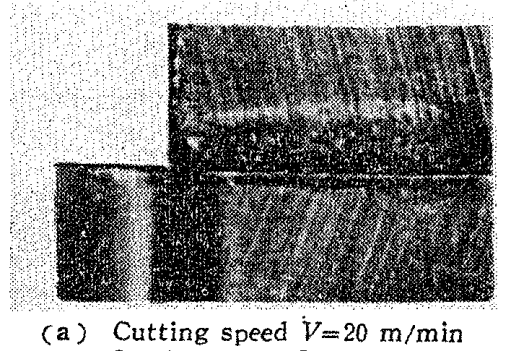

(a) Cutting speed $V=20 \mathrm{~m} / \mathrm{min}$ Cutting time $T=5 \mathrm{sec}$

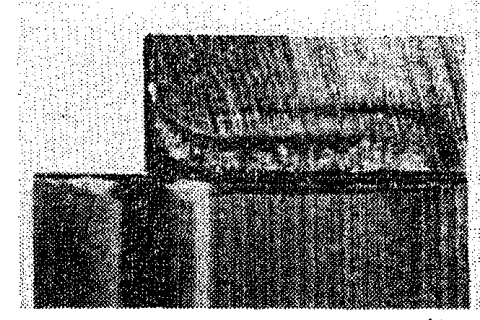

(b) Cutting speed $V=40 \mathrm{~m} / \mathrm{min}$ Cutting time $T=5 \mathrm{sec}$

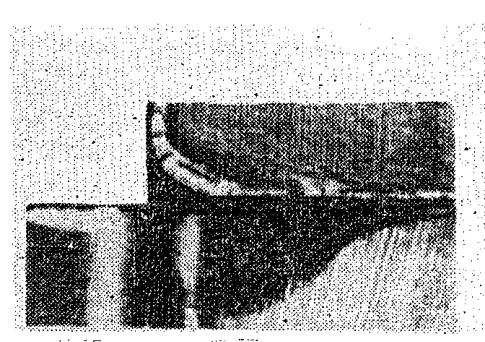

(c) Cutting speed $V=46 \mathrm{~m} / \mathrm{min}$ Cutting time $T=5 \mathrm{sec}$

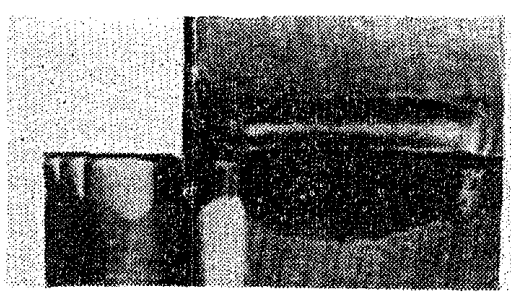

(d) Cutting speed $V=20 \mathrm{~m} / \mathrm{min}$ Cutting time $T=5 \mathrm{~min}$

Tool material: $\mathrm{H} \cdot 3$

Tool geometry: $0,0,5,5,8,0,0.5$

Depth of cut: $2 \mathrm{~mm}$, Feed rate: $0.19 \mathrm{~mm} / \mathrm{rev}$ Fig. 14 Wear after machining chilled roll the cutting edge under the corresponding machining conditions to those of Fig. 14 indicates an obvious sinking of the cutting edge due to the cutting force as the cutting speed increases, which proves that the failure is due to the compressive deformation.

Figure 17, showing the shift of the temperature on the rake face measured by the tool-work thermo. couple method, proves that the temperature reaches a constant value within a few seconds. The temperature on the rake face during the machining of the chilled roll increases monotonously as the machining speed increases, independently of the material, as proved in Fig. 18.

The hardnesses of the rake faces corresponding

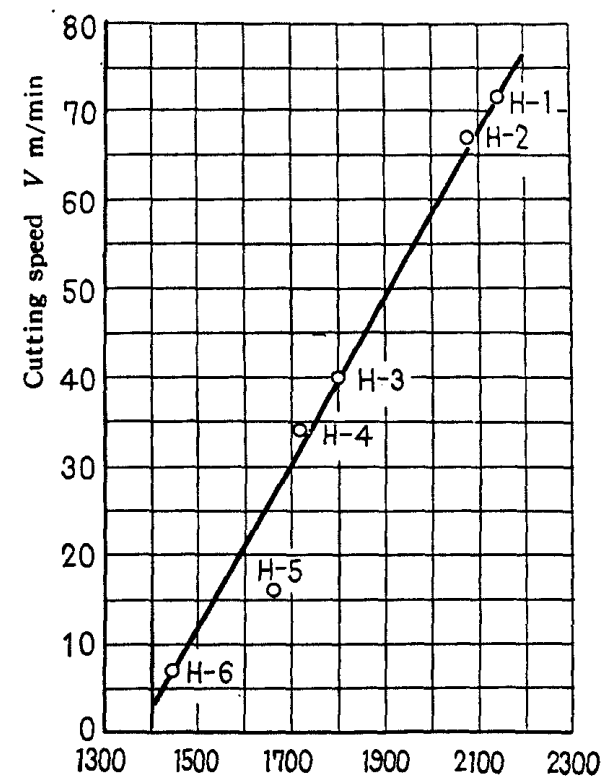

Vickers hardness number of the cutting edges at room temperature

Cutting conditions are the same as Fig. 3

Fig. 15 Cutting speed at which cutting edge begins to fail
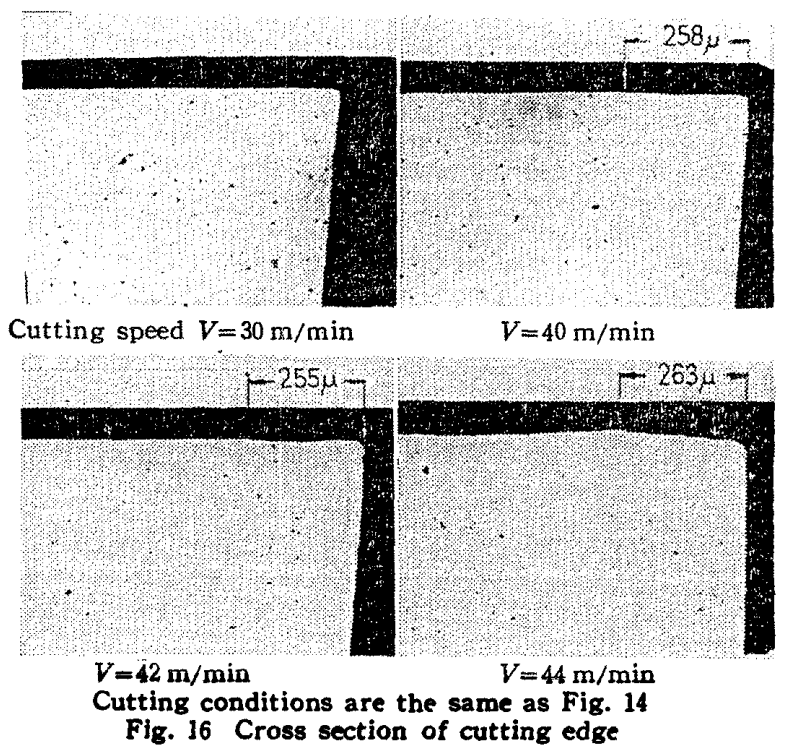
to their temperatures are shown in Fig. 19 for various tool materials; the temperature and hardness of the rake face when the cutting edge begins to fail can be estimated from Figs. 15, 18 and 19.

If the tensile strength (transverse rupture strength) and compressive strength can be measured under this temperature, it can be investigated whether the failure of the cutting edge occurs by the identical method to that used for the experiment described in 4.1 .

Conveniently, the stress distributions at the rake face in the case of the lip angles are large enough, closely resemble to the stress distributions in the case of uniaxial compression. So, we can find that it is not necessary to obtain the bending strength at elevated temperature for the following reason.

Taking into consideration the calculated intensity of mean normal stress on the rake face $\left(\sigma_{1}{ }^{*}+\right.$ $\left.\sigma_{2}^{*}\right) / 2=0.82$ for the lip angle $85 \mathrm{deg}$ as shown in Fig. 12, and the mean normal stress, $\left(\sigma_{1}^{*}+\sigma_{2}^{*}\right) / 2=$ $0.81 \sim 1.08\left(=\sigma_{c}^{*} / 2\right.$, see Table 3$)$ obtained from the uniaxial compression test, it is assumed that there is no great error in substituting the value of the compressive strength at elevated temperature for $\left(\sigma_{1}^{*}-\sigma_{2}^{*}\right)$ on the assumption that in this case the latter is independent of $\left(\sigma_{1}^{*}+\sigma_{2}^{*}\right) / 2$. Here, the compressive strength at elevated temperature is not measured directly. From the solid line in Fig. 20, which shows the relation of the hardness at room

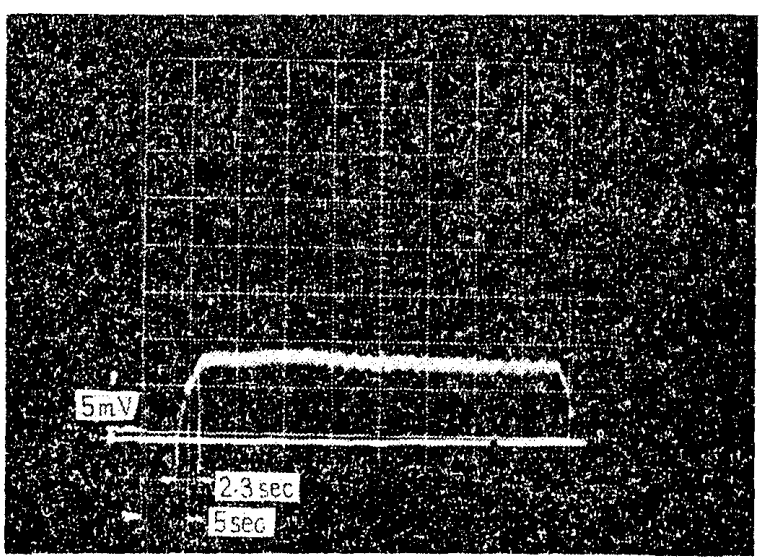

Fig. 17 Temperature on rake face

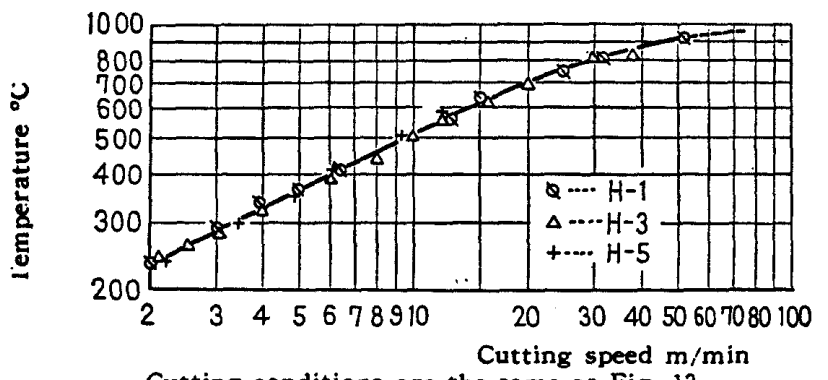

5ig. 18 Cutting speed versus temperature on rake face for various tool materials temperature and the compressive strength, the strength of the tool materials at elevated temperature is given on an extrapolated line corresponding to. the hardness number.

In the compression test, well ground cylindrical bars of cemented carbide $(4.8 \phi \times 4.8 h$ parallelness of both end faces is $2 \mu$ ) of different $C_{0}$ contents with an aluminium foil of $9 \mu$ thick plastered with $\mathrm{Mo}_{2} \mathrm{~S}$ paste on both faces so as to be compressed uniformly without friction were compressed by an. Olsen universal testing machine. Under this method, the values found out are high with less fluctuation than those when the test is carried out without lubricant.

After all, the compressive strength when the cutting edge begins to fail can be found by the steps of procedure listed in Table 4.

The compressive strength when the cutting edge begins to fail is between 249 and $297 \mathrm{~kg} / \mathrm{mm}^{2}$.

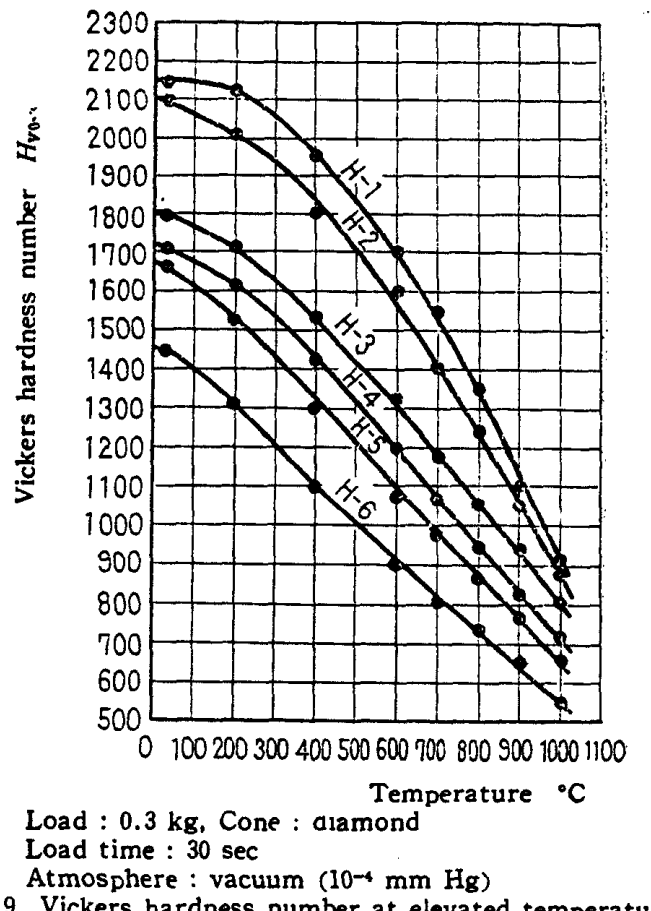

Fig. 19 Vickers hardness number at elevated temperature

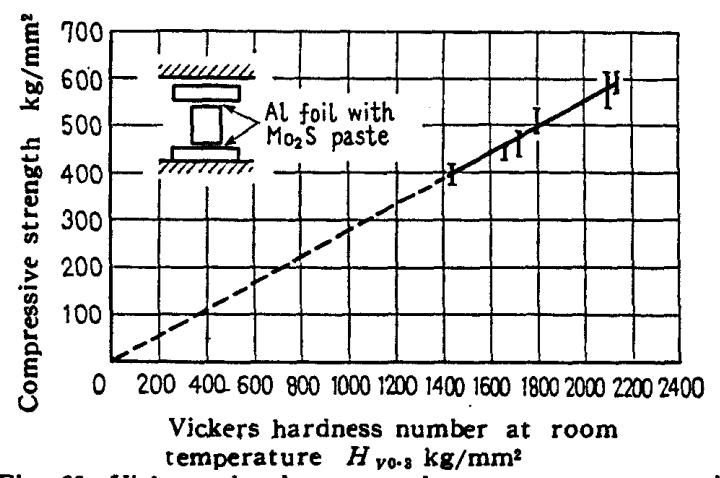

Fig. 20 Vickers hardness number versus compressive strength for various cemented carbides 
although a variance is inevitable to some extent for different Co contents.

On the other hand, the theoretical converted stress is $\sigma_{1}{ }^{*}-\sigma_{2}{ }^{*}=0.959$, then $\sigma_{1}{ }^{*}-\sigma_{2}{ }^{*}=270 \mathrm{~kg} / \mathrm{mm}^{2}$ $\times 0.959=258 \mathrm{~kg} / \mathrm{mm}^{2}$, as shown in Fig. 12 . There. fore, it may be concluded that the values obtained from the experiments are in good agreement with those found through theoretical consideration.

\section{Conclusions}

In spite of many assumptions, the practical values are in good agreement with the theoretical values. Therefore, the assumptions made before the experiments are considered almost reasonable.

Besides, the following facts were confirmed.

(1) For the coefficient of friction 0.431 , the strength of the cutting edge increases not so much as the lip angle increases when the lip angle is above $80^{\circ}$, while in the case of the lip angle being below $60^{\circ}$, the strength of the cutting edge decreases steeply as the lip angle decreases.

(2) When machining hard materials such as chilled cast iron, it is important to consider the compressive strength at elevated temperature of the tool materials, because the values of the strength are in proportion to micro hardness as far as binary tungsten carbide-cobalt alloys are concerned.

\section{Acknowledgements}

The author would like to acknowledge the advices given by Prof. S. Masuko and Assistant Prof. E. Usui of the Tokyo Institute of Technology.

\section{References}

(1) F.R. Archibald: Trans. ASME, Vol. 78 (1956-8), p. 1149.

(2) S. Timoshenko and J.N. Goodier: Theory of Elasticily 2 nd ed., (1951) McGrow-Hill.

(3) M. Masuda and T. Murata: Kogyo sosel Rikigaku, (Theory of plasticity in Technology), $3 \mathrm{rd}$ ed., (1963), Yokendo.

Table 4 Procedure for obtaining the compressive strength of the cutting edges made of various cemented carbides when failure occurred

\begin{tabular}{|c|c|c|c|c|c|c|}
\hline & \multicolumn{5}{|c|}{ Experimental value } & \multirow{3}{*}{$\begin{array}{l}\text { Calculated } \\
\text { value }\end{array}$} \\
\hline & \multirow{2}{*}{$\begin{array}{l}\text { Vickers hardness } \\
\text { number at room } \\
\text { temperature }\end{array}$} & \multicolumn{4}{|c|}{$\begin{array}{l}\text { When the failure occurs at the cutting edge owing to the } \\
\text { thermal softening }\end{array}$} & \\
\hline & & Cutting speed & Rake face temp. & Vickers hardness & $\begin{array}{l}\text { Compressive } \\
\text { strength }\end{array}$ & \\
\hline Marks & $H_{Y 0 \cdot 3}$ & $V_{c} \mathrm{~m} / \mathrm{min}$ & ${ }^{\circ} \mathrm{C}$ & $H_{V 0.5}$ & $\sigma_{c} \mathrm{~kg} / \mathrm{mm}^{2}$ & $\mathrm{~kg} / \mathrm{mm}^{2}$ \\
\hline $\mathrm{H}-1$ & 2146 & 71.4 & 952 & 1008 & 281 & 258 \\
\hline $\mathrm{H}-2$ & 2093 & 67.5 & 946 & $؟ 81$ & 276 & $"$ \\
\hline $\mathrm{H}-3$ & 1796 & 40.1 & 868 & 928 & 258 & $"$ \\
\hline $\mathrm{H}-4$ & 1710 & 34.2 & 837 & 893 & 249 & $"$ \\
\hline $\mathrm{H}-5$ & 1661 & 16.6 & 624 & 1065 & 294 & $"$ \\
\hline $\mathrm{H}-6$ & 1446 & 6.8 & 423 & 1076 & 297 & $"$ \\
\hline .. & $\begin{array}{l}\text { In case of } 30 \mathrm{~kg} \\
\text { loaded crack was } \\
\text { observed at in- } \\
\text { tended corner }\end{array}$ & From Fig. 15 & From Fig. 18 & From Fig. 19 & From Fig. 20 & $\begin{array}{l}\text { From Fig. } 10 \\
\sigma_{1} *-\sigma_{2} *=0.959 \\
\sigma_{1}-\sigma_{2}=270 \times 0.959_{s}\end{array}$ \\
\hline
\end{tabular}

